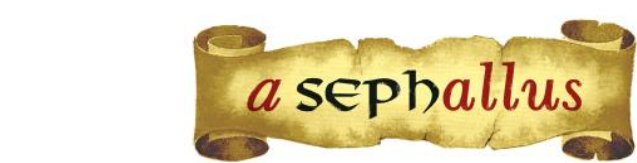

Revista aSEPHallus de Orientação Lacaniana

Núcleo Sephora de Pesquisa sobre o Moderno e o Contemporâneo

ISSN $1809-709$ X

\title{
O desmentido é um artifício utilizado pelo cínico para lidar com a existência do Outro
}

\author{
Angélica Cantarella Tironi \\ Psicanalista \\ Graduada Psicóloga pela Pontifícia Universidade Católica do Rio de Janeiro (PUC-Rio) \\ Mestre e Doutora pelo Programa de Pós-Graduação em Psicanálise da Universidade do Estado do Rio \\ de Janeiro (UERJ) \\ Pós-Doutoranda do Programa de Pós-Graduação em Teoria Psicanalítica da Universidade Federal do \\ Rio de Janeiro (UFRJ) \\ Correspondente da Seção Rio de Janeiro da Escola Brasileira de Psicanálise (EBP-RJ) \\ Membro do Instituto Sephora de Ensino e Pesquisa de Orientação Lacaniana (ISEPOL) \\ E-mail: angelicatironi@gmail.com
}

\begin{abstract}
Resumo: As grandes narrativas comunitárias que veiculavam as tradições deram lugar a uma multiplicidade de pequenos pactos acordados entre pares. Configurados como tribos, munidos de uma retórica própria, os neuróticos aproveitaram para sair em defesa da universalização de modos particulares de gozo por meio do desmentido banal, artifício que franqueia, de uma só vez, a castração e a satisfação irrestrita da pulsão. Desta forma, o que nas neuroses clássicas é do campo do conflito e da formação dos sintomas, em alguns casos encontra uma solução distinta, que faz com que a empatia, a vergonha e a moralidade coexistam em harmonia com a violência, a obscenidade e a impulsividade.
\end{abstract}

Palavras-chave: psicanálise; desmentido banal; cinismo; violência; justiceiros.

\section{Le démenti est un artifice utilisé par le cynique pour faire face à l'existence de l'Autre}

Résumé: Les grands récits communautaires qui transmettaient les traditions ont donné lieu à une multiplicité de petits pactes formés entre pairs. Organisés en tribus, munis de leur propre rhétorique, les névrotiques en ont profité pour défendre l'universalisation des modes particuliers de jouissance par un démenti banal, un artifice qui permet, à la fois, de la castration et de la satisfaction illimitée de la pulsion. De cette façon, ce qui, dans les névroses classiques, appartient au champ du conflit et de la formation des symptômes, dans ces cas, trouve une solution distincte, ce qui fait que l'empathie, la honte et la morale coexistent en harmonie avec la violence, l'obscénité et l'impulsivité .

Mots-clés: psychanalyse; démenti banal; cynisme; violence; justiceurs.

\section{The denial is an artifice used by the cynic to deal with the existence of the Other}

Abstract: Large community narratives that transmitted the traditions gave way to a multiplicity of small pacts agreed between pairs. Configured as tribes, equipped with a rhetoric of their own, the neurotics took the opportunity to come out in defense of the universalization of particular modes of enjoyment through basic denial, an artifice that franchises, at one time, the castration and the unrestricted pulsion satisfaction. Thus, what in classic neuroses is the field of conflict and the formation of symptoms, in some cases finds a distinct solution, which makes empathy, shame and morality coexist in harmony with violence, obscenity and impulsivity. Keywords: psychoanalysis; banal denial; cynicism; violence; vigilantes. 


\section{O desmentido é um artifício utilizado pelo cínico para lidar com a existência do Outro}

\section{Angélica Cantarella Tironi}

A grande narrativa simbólica que até o século passado legitimou as conviç̧ões socialmente partilhadas sofreu transformações em decorrência da modificação da modalidade do capitalismo de produção para o de consumo. 0 capitalismo de produção preconizava a sobrevivência, e todos os esforços de trabalho não iam além do intuito de prover as necessidades da própria família. Plantava-se, produzia-se uma quantidade suficiente para alimentar seus membros e obter outras mercadorias fundamentais à subsistência. Muitas vezes a troca de insumos, o escambo, era a forma de alcançar o que não se tinha.

No entanto, o capitalismo de consumo colocou novas regras na maneira de produzir. Pretendia-se inundar o mercado com uma quantidade enorme de bens de consumo, cada vez mais diversificado. Por outro lado, necessitava-se o consumo destas ofertas, e para tanto, era preciso o acúmulo de capital que permitisse os trabalhadores absorverem as ofertas disponibilizadas pelo capitalismo. Nesta nova lógica, a sobrevivência foi substituída pelo acúmulo e os trabalhadores se tornaram consumidores.

Esta mudança incidiu diretamente sobre a economia psíquica dos sujeitos e gerou efeitos subjetivos importantes, na medida em que os campos da linguagem e das pulsões foram radicalmente afetados. Uma modificação na vociferação do supereu e na satisfação dos circuitos pulsionais pode ser claramente constatada na clínica, exigindo um reposicionamento do analista na direção do tratamento.

No cotidiano da clínica, neuróticos regidos pela ética tradicional testemunham os efeitos dos valores veiculados pelo discurso religioso judaico-cristão, no qual o supereu autoritário, a consciência moral, os ideais sociais, o mecanismo de recalque e a formação de sintomas orientam a satisfação pulsional pelas vias da disciplina, do autocontrole, da renúncia e da abstinência. Mas, ao mesmo tempo, um outro discurso se apresenta, de natureza bastante distinto. Trata-se do gozo, fundamentado em imperativos não identificados nem a ideais sociais repressivos, nem ao sentimento inconsciente de culpa. Ele desfaz a operatividade da ética tradicional ao colocar o caráter polimórfico das pulsões e as fantasias sádicas no comando.

Jacques Lacan evidenciou essa faceta de forma mais apropriada ao relacionar o supereu a uma lei de caráter insensato: "o supereu é, a um só tempo, a lei e a sua destruição" (Lacan, 19531954/1986, p. 123). Ele é um Tu deves, uma força imperiosa privada de qualquer regulação. A essência deste supereu se origina em um pai que, por não estar submetido à castração, apela a um gozo puro, impossível de se obter. E, paradoxalmente, origina tudo aquilo que se define como consciência moral. "Nada força ninguém a gozar, senão o superego" (Lacan, 1971/2009, p. 166) que, tal como o capitalismo de consumo, seduz o sujeito para que ele não ceda de seu desejo. 
Quando o gozo não está temperado pela ética da renúncia, a violência, a obscenidade, e a avidez não suscitam vergonha, e o gozo particular, que deveria estar restrito ao âmbito privado, se mostra socialmente sem pudores. As transgressões se tornam fenômenos habituais e corriqueiros, a certeza na impunidade surge em detrimento à crença nas leis. Esses sujeitos tratam seus desejos como a ordem do dia e fazem com que eles sejam satisfeitos muitas vezes à apensa do outro, sempre em benefício próprio, sem se importar com questões morais.

No entanto, o que escuto na clínica não é um neurótico completamente livre de suas atribuições inconscientes e regido somente pela própria vontade de gozar. Mas também não é aquele no qual o sentimento inconsciente de culpa o força a renunciar seu gozo particular, caso este gozo esteja contra os ideais normativos socialmente partilhados. Trata-se de um neurótico em que a faceta superegóica que instrumentaliza os fantasmas sádicos a céu aberto prevalece, em detrimento do supereu pautado nos ideais sociais e na repressão da satisfação pulsional.

O termo prevalência está sendo utilizado para ressaltar que este sujeito faz coexistir a ética da renúncia e o gozo por meio de um artifício que franqueia, de uma só vez, a castração e a satisfação irrestrita da pulsão. Desta forma, o que nas neuroses clássicas é do campo do conflito e da formação dos sintomas, nesses casos encontra uma solução distinta, na qual a empatia, a vergonha e a moralidade coexistem em harmonia com a violência, a obscenidade e a impulsividade.

O conceito de perverso puritano, de Dany-Robert Dufour, descreve um sujeito capaz de fazer coexistir duas ordens distintas, tal como o neurótico sobre o qual este artigo disserta. No entanto, ao contrário do neurótico que evidencio, para Dufour, estas ordens são conflituosas e necessitam encontrar uma forma de apaziguar estas diferenças por meio de soluções de compromisso. Segundo este autor, trata-se de um sujeito em que:

[...] o perverso por ele abrigado desfruta sadicamente do neurótico puritano, enquanto o puritano suporta o perverso, vale dizer, dele desfruta masoquisticamente. Trata-se, portanto, de um sujeito que em si mesmo é disputado pelo bem e o mal sem fim nem solução. Mas a expressão também designa o sujeito que terá sido obrigado a encontrar uma solução de compromisso para aplacar esse conflito. (Dufour, 2013, p. 76)

Esse sujeito encontrou uma maneira muito peculiar de suspender os conflitos neuróticos, elevando os vícios privados à dignidade de virtudes públicas, enaltecendo o amor próprio e fazendo avançar as ideologias do capitalismo de consumo. Tal como a moral de $A$ fábula das abelhas, de Mandeville: "os vícios privados fazem o bem público e a virtude condena uma grande cidade à pobreza e à indigência" (Mandeville apud Dufour, 2013, p. 112). Para que a solução de compromisso proposta por Dufour se realize, deve-se supor que "o universo humano é organizado, sem que os indivíduos o saibam, por um jogo de forças que repousa no princípio do interesse pessoal" (Dufour, 
2013, p. 122). Esta ordem natural virtuosa é capaz de regular os vícios excessivos, tal como Adam Smith supunha com a teoria da mão invisível.

No entanto, esses operadores teóricos não valem para o sujeito que este artigo evidencia, pois quando se está no domínio da prevalência do gozo, não há nenhuma ordem virtuosa que faça frente ao imperativo de satisfação de um vício. Quanto mais quando se considera as características do capitalismo de consumo, que exige uma desconstrução do Outro do saber que encerre o valor da transmissão nas sucessões geracionais, a crença na satisfação completa e irrestrita da pulsão e uma desvalorização do objeto, que passa a fazer parte de uma série metonímica cuja finalidade é sempre o descarte.

De que forma um sujeito pode suspender seus conflitos neuróticos na era do capitalismo de consumo? Aqui, o perverso puritano não sabe muito bem como se virar, mas o cínico - uma das formas do neurótico que estou descrevendo se posicionar - se prolifera com notória habilidade. Ele faz uso do que o capitalismo de consumo oferece a favor da sua ética do gozo. E a melhor maneira que encontrou foi por meio do desmentido banal, que relativiza o Outro a ponto de convencer os débeis de que Ele não existe. E acrescenta: se o Outro está morto, então tudo é permitido.

\section{Sobre o desmentido banal}

O desmentido banalé uma proposição clínica de Coelho dos Santos (2016) sobre o estatuto do Outro na contemporaneidade. Segundo a autora, a tese de Jacques-Alain Miller de que o "Outro não existe", não é a melhor maneira para se apreender a configuração de valores em voga na contemporaneidade. Ela defende que as coordenadas tradicionais que sustentam a lei simbólica como agente da castração existem ainda hoje, mas estão sendo desmentidas na atualidade, interferido em todas as formas de autoridade e na operatividade do supereu. Como consequência, a tese freudiana de que a neurose é o negativo da perversão se encontra subvertida, pois, as fantasias perversas são instigadas a se expressarem sem véu, ignorando o mecanismo do recalque (Coelho dos Santos, 2015).

O desmentido banal é uma forma de negação bastante peculiar, que encontra na obra freudiana uma atenção especial. Segundo Freud, desde o início, o ego precisa mediar as relações entre o id e o mundo externo. Se inicialmente ele protege o id contra os perigos externos, logo em seguida o ego adota uma atitude defensiva em relação ao próprio id, considerando que algumas satisfações pulsionais conduzem a sérios riscos. Regido pelo princípio de prazer, o aparelho psíquico tenta, a todo custo, "evitar o perigo, a ansiedade e o desprazer" (Freud, 1937/1996, p. 252). Se uma percepção da realidade for a causa do desprazer, ela pode ser evitada através da fuga. No entanto, a fuga não auxilia o ego em relação aos perigos internos. Para se proteger destas ameaças, o ego lança mão de mecanismos de defesa, que distorcem a percepção interna e fornecem uma representação falsificada do id. Assim, diante do conflito entre a exigência de satisfação pulsional e a proibição desta satisfação por parte da realidade, a criança tem duas possibilidades: renuncia à 
satisfação ou rejeita a realidade. Na maior parte dos casos de neurose, sob o domínio do princípio de realidade, ela se desvincula das exigências pulsionais indesejáveis através do mecanismo de recalque (Freud, 1940[1938]/1996).

No entanto, com frequência, o ego utiliza outro recurso - além do recalque - para lidar com as percepções aflitivas. Ele se desvia destas percepções por meio da negação (Verleugnen), assumindo, simultaneamente, duas atitudes contraditórias. Diante da diferença entre os sexos, o ego rejeita a realidade (nega que não viu um pênis nos genitais femininos) ao mesmo tempo em que reconhece que as mulheres não possuem pênis: "quando um menino pela primeira vez chega a ver a região genital de uma menina, começa por demonstrar irresolução ou falta de interesse; não vê nada ou rejeita o que viu, abranda a expressão dele ou procura expedientes para colocá-lo de acordo com suas expectativas" (Freud, 1925/1996, p. 281).

A negação (Verleugnen) é sempre suplementada por um reconhecimento e permite que duas atitudes contrárias e independentes persistam, sem se influenciarem mutuamente. Este arranjo só pode ser realizado ao custo de uma divisão do ego (splitting). A atitude que se ajusta ao desejo e a atitude que se ajusta à realidade existem lado a lado e o sujeito oscila entre as duas possibilidades. $O$ resultado depende de qual das duas atitudes prevalece com maior intensidade.

Diferente do que ocorre nas neuroses, na perversão não há uma divisão do ego, o princípio de prazer prevalece sobre o princípio de realidade, e as duas proposições contraditórias se arranjam em uma conciliação através do fetiche. Diante da diferença sexual, o menino se recusa a aceitar que as mulheres não possuem pênis, pois, ao reconhecê-las castradas, a posse do seu próprio pênis se encontra em perigo. $O$ conflito entre a rejeição e o reconhecimento da castração se conclui em uma conciliação que mantém o pênis nas mulheres, no entanto, um pênis distinto daquele que ele acreditou que sua mãe possuía.

O fetiche é este pênis distinto, um "substituto simbólico do pênis" (Freud, 1940[1938]a/1996, p. 216) da mulher (da mãe) que o menino não deseja abandonar. Através do fetiche o menino rejeita a realidade da castração e substitui o pênis ausente nas mulheres por uma parte do corpo feminino ou por um objeto. Esse deslocamento ocorre apenas em relação ao corpo feminino, com referência a seu próprio pênis, nada se modifica. Assim, o fetiche protege contra a ameaça de castração e permite o homem dotar as mulheres de características que as torna toleráveis como objetos sexuais.

Os mecanismos de defesa servem para o ego manter afastado os perigos que o ameaçam. No entanto, eles mesmos poder se tornar uma ameaça, cobrando do ego um preço muito alto pelos serviços prestados. Esses mecanismos se fixam no ego e se tornam "modalidades regulares de reação de seu caráter, as quais são repetidas durante toda a vida, sempre que ocorre uma situação semelhante à original" (Freud, 1937/1996, p. 254). Independente do que o ego faça para se defender - negar uma parte de realidade ou rejeitar uma exigência pulsional -, o esforço para se desligar da realidade nunca é completo e conduz inevitavelmente a complicações psíquicas. 
Este tipo de negação (Verleugnen), encontrada em alguns casos de neurose, esclarece certos fenômenos comuns na contemporaneidade, tais como o cinismo e o relativismo. Neles, duas afirmações distintas coexistem simultaneamente, sem se oporem ou se excluírem. Para que esta coexistência seja possível, é necessário que o lugar da verdade esteja fragilizado no campo simbólico.

\section{O capitalismo cínico}

O capitalismo de consumo rebaixou a lei simbólica à normas sociais. As grandes narrativas comunitárias que veiculavam as tradições deram lugar a uma multiplicidade de pequenos pactos acordados entre pares. Configurados como tribos, munidos de uma retórica própria, estes neuróticos saíram em defesa da universalização de modos particulares de gozo. De que forma? Regulamentando o "tudo é relativo" como discurso dominante.

O relativismo fortaleceu o surgimento de saberes pseudocientíficos, que atualmente concorrem em igualdade de condições com saberes tradicionais solidamente estabelecidos. O Outro do saber - da religião e da ciência - se converteu em fóruns de discussão que emitem opiniões especializadas para todo assunto e acolhem qualquer um que acredite ter o que dizer. Quando o lugar da verdade não está mais garantido, esse neurótico se aproveita para manipular as massas em favor de seus interesses particulares.

Este fato pode ser ilustrado pela célebre fala de Churchill: "Só podemos confiar em uma estatística quando nós mesmos a falsificamos" (Sloterdijk, 2012, p. 387). Para que esta lógica funcione é necessário que as massas estejam a tal ponto débeis, que não seja possível nenhuma análise crítica que desmascare os verdadeiros interesses por trás das ideologias propagadas (Miller, 1996-1997/2005, p. 39).

1984, escrito por George Orwell no fim da década de 1940, é uma fiç̧ão que ilustra de forma precisa as consequências desta debilidade e da manipulação da verdade, através do relativismo. 0 romance se passa na Oceania, estado controlado pela ditadura do Partido e comandado pelo Grande Irmão. Ali nada era ilegal, pois não haviam leis. A obediência irrestrita de pensamento e ação era a única regra a ser cumprida. Esta ortodoxia política era realizada por dispositivos de vigilância como a teletela, a patrulha policial e a Polícia das Ideias.

O Departamento de Documentação, braço importante do Ministério da Verdade, reformulava todo tipo de literatura ou documentação que tivesse algum significado político ou ideológico. Depois de efetuadas todas as correções necessárias, a edição era reimpressa, o original destruído e a cópia corrigida era arquivada. Esse processo de alteração contínua atualizava o passado para confirmar, com provas documentais, que todas as previsões realizadas pelo Partido foram acertadas. Reescrevendo a história, alterando os arquivos, retificando as estatísticas para fazê-las corresponder aos resultados almejados, o Partido contava sua própria verdade, eliminando qualquer indício que poderia confrontar suas afirmações: "a mentira tornava-se história e virava verdade" (Orwell, 2009, p. 47). 
Em Novafala, língua oficial da Oceania, o controle da realidade era realizado pelos princípios do duplipensamento. Algumas palavras comportavam dois sentidos contraditórios que poderiam ser um elogio ou uma ofensa, de acordo com o contexto em que era aplicada. A definição deste desmentido, nas palavras de Orwell:

Saber e não saber, estar consciente de mostrar-se cem por cento confiável ao contar mentiras construídas laboriosamente, defender ao mesmo tempo duas opiniões que se anulam uma à outra, sabendo que são contraditórias e acreditando nas duas; recorrer à lógica para questionar a lógica, repudiar a moralidade dizendo-se um moralista, acreditar que a democracia era impossível e que o Partido era o guardião da democracia; esquecer tudo o que fosse preciso esquecer, depois reinstalar o esquecido na memória no momento em que ele se mostrasse necessário, depois esquecer tudo de novo sem o menor problema; e, acima de tudo, aplicar o mesmo processo ao processo em si. (Orwell, 2009, p. 48)

Segundo Orwell, os valores do Partido eram adotados com maior convicção pelas pessoas que não tinham capacidade de compreendê-los. Elas nunca estavam interessadas nos acontecimentos públicos, o que facilitava que acreditassem nas maiores deturpações da realidade. Uma debilidade bastante atual na contemporaneidade, fruto de um desinteresse maciço nos movimentos do mundo e de um excesso de informações que permite a distorção de fatos e a relativização da verdade.

Mas na atualidade, não é preciso se valer apenas a literatura para ilustrar como a verdade pode ser relativizada. Na política de nosso país existe uma infinidade de exemplos desta manipulação, muitos deles beiram à comédia. Sobre a OAS ter gasto 1,3 milhões de reais para financiar o transporte e o armazenamento dos objetos pessoais do ex-presidente Luiz Inácio Lula da Silva, Paulo Okamotto disse que: "A OAS, para mim, deveria inclusive reivindicar a Lei Rouanet, porque está fazendo um pagamento para manter um bem cultural do povo brasileiro"1.

Outro exemplo deste manejo da verdade vem de Alberto Youssef que, inquirido pelo juiz Sergio Moro pela segunda vez, disse em sua defesa: "Eu podia ter ficado com aquele dinheiro que ganhei do Banestado e ter ficado em casa. Mas não. Preferi investir esse dinheiro no mercado, correr risco que o empresário corre no país hoje para montar uma empresa, em dar empregos e em pagar impostos" (Youssef apud Netto, 2016, p. 182).

Uma outra expressão contemporânea desta neurose relativista é o cinismo. Segundo Sloterdijk (2012, p. 31), "o mal-estar na cultura assumiu uma nova qualidade: ele aparece como um difuso cinismo universal". O cinismo é uma posição subjetiva bastante particular, mas não rara na atualidade. Sua lógica é a de "autodesmentir" a ética tradicional e as convenções sociais, para demonstrar que "as leis comuns existem somente para os tolos" (Sloterdijk, 2012, p. 32). 
O cínico estabelece uma relação com as normas a partir de critérios que fazem com que elas muitas vezes pareçam o contrário do que realmente pretendem indexar (Safatle, 2008, p. 139). Flexibilizando as identidades, absorvendo a diferença, fragilizando os vínculos, o cínico relativiza o Outro a tal ponto que as lógicas norma-transgressão, verdade-mentira, certo-errado deixam de operar. Elas se tornam apenas um ponto de vista dentro de uma infinidade de pontos de vista que se pode ter sobre determinada situação, pois se não há nenhuma referência que sirva de medida da verdade para uma hierarquização de valores, todo modo de existir é válido.

Na era do capitalismo de consumo, o neurótico clássico não sabe muito bem como se virar, mas o cínico se prolifera com notória habilidade, pois sabe fazer uso do que o capitalismo de consumo oferece a favor de seu gozo. O que o capitalismo de consumo, o cínico e as massas tem em comum? Todos militam pela universalidade dos direitos. Direito a que? Bem, aí cada um reponde a partir de seus próprios interesses. O capitalista diz que todos devem ter direito ao consumo, o cínico diz que todos devem ter direito a gozar de sua própria maneira, enquanto o neurótico, que ainda não entendeu do que se trata, se reúne em mobilizações sociais em busca de uma sociedade igualitária de direitos, mais tolerante em relação às diversidades.

Diante deste cenário, uma questão imediatamente se coloca: porque os fenômenos de violência crescem tanto exatamente quando se institui um discurso de diversidade e tolerância às diferenças? O que o capitalismo de consumo e o cinismo tem a ver com isso?

\section{A violência na era dos desmentidos}

A violência é um assunto recorrente na atualidade do Rio de Janeiro. Se a tão pouco tempo acreditava-se que ela se contextualizava nas comunidades favelizadas e dizia respeito à guerra do tráfico, à compra e venda de armas de fogo e à disputa dos pontos de comercialização das drogas nos morros, atualmente seu espectro se torna cada vez mais amplo. Os jornais confirmam que a violência se generalizou no dia-a-dia do asfalto e mostram que o que estava a cargo da polícia e dos agentes judiciários agora está sendo assumido pela população. O cidadão comum se imbuiu do direito de fazer justiça com as próprias mãos depois de eleger e julgar sumariamente suas vítimas.

Alegando descrença nas leis, na Justiça e no aparato policial, rapazes de classe média, estudantes e profissionais aplicados, sem nenhum antecedente criminal, se reuniram sob a insígnia justiceiros, e justificaram seus atos violentos se dizendo amedrontados pelos altos índices de violência urbana. A lógica cínica embutida nesta cultura da violência e do ódio esconde que o desejo de agressão e de destruição muitas vezes subjaz sob motivos "de natureza erótica e idealista" (Freud, 1933[1932]/1996). As maiores atrocidades cometidas nas guerras e na Inquisição, por exemplo, atestam a força da pulsão destrutiva, mesmo que ela esteja velada por motivos nobres ou não seja claramente declarada. Quando se relativiza as leis a ponto de fazer crer que não é o homem quem deve servir à lei, mas a lei que deve servir ao homem, atos explícitos de violência, por exemplo, passam a ser considerados atos de justiça e de coragem. 
Por meio do desmentido banal, o neurótico clássico conseguiu fazer coexistir a castração e a satisfação irrestrita da pulsão. De forma cínica, esse neurótico lida com a vida como se seu inconsciente não fosse determinado pela ética tradicional. Desta forma, ele pode estar, ao mesmo tempo, dentro e fora da lei, sendo, de uma só vez, o respeitado sujeito de família e o temido justiceiro.

\section{O exibicionismo na era do consumo}

O capitalismo de consumo aproveitou a cultura da violência para expandir seus mercados e ofertar a vigilância eletrônica para o mundo todo. Veiculando estatísticas que alertam sobre o aumento da taxa de criminalidade, essas tecnologias se tornaram uma obsessão que inaugura uma sociedade de controle com espectro nunca antes visto. No entanto, o que se esconde por trás deste domínio do olhar justificado pela necessidade de uma vigilância rigorosa é uma articulação estreita entre a sociedade da vigilância e a sociedade do espetáculo (Wajcman, 2011, p. 80).

O capitalismo de consumo colocou a intimidade no mercado e ofereceu um cardápio imenso de novas satisfações com o objeto olhar. Se na ética tradicional o olhar autoritário decorrente do supereu fomentava satisfações pela adequação do sujeito aos elementos do Ideal do eu - a disciplina e a moral -, atualmente evidencia-se uma sociedade onde se impera a transparência e que aspira tudo ver e tudo exibir.

Fotos, vídeos e postagens de crimes e de atos cruéis são cada vez mais comuns nas redes sociais. Em seus perfis, bandidos e faç̧ões criminosas estão usando a internet para divulgar seus feitos, assumirem a autoria de crimes e fazerem ameaças à polícia. $\mathrm{O}$ comportamento exibicionista destas pessoas revela a ousadia de ostentarem publicamente os crimes que cometem.

Não só a criminalidade, mas também a intimidade dos casais tem sido um assunto recorrente na internet. A nova mania do selfie, no Instagran, são as imagens dos casais após o sexo, seguidas pela hashtag \#aftersex. Além dela, com a hashtag \#deliveryroom é possível encontrar inúmeros selfies realizados durante trabalhos de parto. Este material, que anteriormente compunha os elementos privados da vida, agora é exibido e compartilhado nas redes sociais.

O gozo de tornar público aquilo que há pouco era da ordem do privado, atualmente vem sendo pleiteado como um direito. Até onde se pode dizer que algo é obsceno diante da naturalidade com que a sexualidade e a violência vêm circulando na atualidade? Segundo Jacques-Alain Miller (2003, p. 12), na década de 70, Lacan denunciou que "a vergonha não estava mais em circulação", pois o olhar do Outro capaz de julgar e provocar vergonha se dissipara em prol de um sujeito que goza ao olhar o espetáculo da obscenidade, da carnificina e do horror disseminado na mídia globalizada. O que o cínico tentou esconder do neurótico clássico, mas o capitalismo de consumo escancarou, pode ser resumido na seguinte formulação: "olhem eles gozarem para gozarem disso" (Miller, 2003, p. 11). 


\section{Nota:}

1 http://politica.estadao.com.br/blogs/fausto-macedo/oas-deveria-reivindicar-lei-rouanet-para-quardar-acervode-lula-diz-okamotto/.

\section{Referências Bibliográficas}

Coelho dos Santos, T. (2015). O olhar sem véu: transparência e obscenidade. Revista aSEPHallus de Orientação Lacaniana, 10(20), 4-15. Recuperado de: http://www.isepol.com/asephallus/numero 20/pdf/o olhar sem veu.pdf.

Coelho dos Santos, T. (2016). Desmentido ou inexistência do Outro: a era da pós-verdade. Revista aSEPHallus de Orientação Lacaniana, 11(22), 4-19. Recuperado de: http://www.isepol.com/asephallus/numero 22/pdf/2-

Desmentido ou inexistencia do Outro.pdf.

Dufour, D.-R. (2013). A cidade perversa: liberalismo e pornografia. Rio de Janeiro: Civilização Brasileira

Freud, S. (1996). Algumas consequências psíquicas da distinção anatômica entre os sexos. Edição standard brasileira das obras psicológicas completas de Sigmund Freud (Vol. 19, 271-286). Rio de Janeiro: Imago (Texto originalmente publicado em 1925).

Freud, S. (2014). A negação. São Paulo: Cosac Naify (Texto originalmente publicado em 1925).

Freud, S. (1996). Análise terminável e interminável. Edição standard brasileira das obras psicológicas completas de Sigmund Freud (Vol. 23, 223-270). Rio de Janeiro: Imago (Texto originalmente publicado em 1937).

Freud, S. (1996). Esboço de psicanálise. Edição standard brasileira das obras psicológicas completas de Sigmund Freud (Vol. 23, 151-221). Rio de Janeiro: Imago (Texto originalmente publicado em 1940[1938]a).

Freud, S. (1996). A divisão do ego no processo de defesa. Edição standard brasileira das obras psicológicas completas de Sigmund Freud (Vol. 23, 289-296). Rio de Janeiro: Imago (Texto originalmente publicado em 1940[1938]b).

Freud, S. (1996). Fetichismo. Edição standard brasileira das obras psicológicas completas de Sigmund Freud (Vol. 21, 149-160). Rio de Janeiro: Imago (Texto originalmente publicado em 1927).

Miller, J.-A. (2005). El Otro que no existe y sus comités de ética. Buenos Aires: Paidós (Seminário originalmente publicado em 1996-1997).

Netto, V. (2016). Lava Jato: o juiz Sergio Moro e os bastidores da operação que abalou o Brasil. Rio de Janeiro: Primeira Pessoa.

Orwell, G. (2009). 1984. São Paulo: Companhia das Letras.

Saflate, V. (2008). Cinismo e falência da crítica. São Paulo: Boitempo.

Sloterdijk, P. (2012). Crítica da razão cínica. São Paulo: Estação Liberdade. 
Citacão/Citation: Tironi, A. C. (mai. a out. 2017). O desmentido é um artifício utilizado pelo cínico para lidar com a existência do Outro. Revista aSEPHallus de Orientação Lacaniana, 12(24), 92-102. Disponível em www.isepol.com/asephallus. doi: 10.17852/1809-709x.2019v12n24p92-102.

Editor do artigo: Tania Coelho dos Santos.

Recebido/Received: 24/06/2017 / 06/24/2017.

Aceito/Accepted: 18/07/2017 / 07/18/2017.

Copyright: (C) 2013 Associação Núcleo Sephora de Pesquisa sobre o moderno e o contemporâneo. Este é um artigo de livre acesso, que permite uso irrestrito, distribuição e reprodução em qualquer meio, desde que o autor e a fonte sejam citados/This is an open-access article, which permites unrestricted use, distribution, and reproduction in any medium, provided the author and source are credited. 